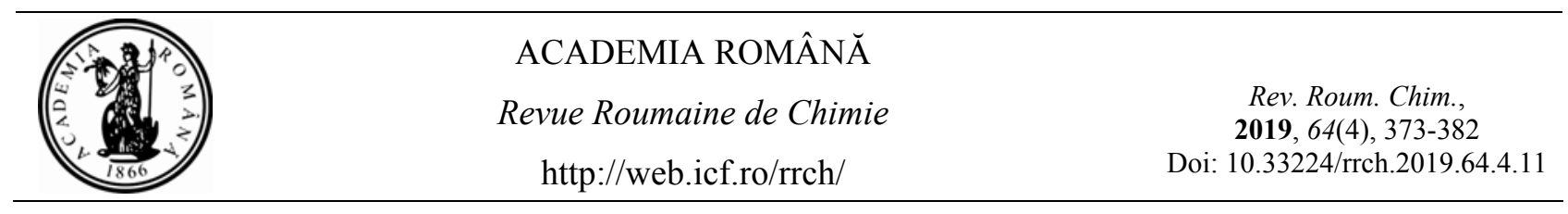

\title{
CHEMICAL COMPOUNDS FROM HUMAN RESPIRATION
}

\author{
Cristina POPA, ${ }^{*}$ Ana Maria BRATU and Mioara PETRUS \\ Department of Lasers, National Institute for Laser, Plasma, and Radiation Physics, \\ 409 Atomistilor St., PO Box MG-36, 077125 Bucharest, Roumania
}

Received December 12, 2018

Ethylene, methanol, ethanol, and ammonia are nowadays known indirect biomarkers for various diseases and malfunctions of the human body.

The objective of the present research was to investigate the origin of the trace volatile compounds observed in breath exhaled via the mouth, which is the usual way to carry out breath analysis. Therefore, we have initiated experiments to measure the concentration of the ammonia, ethylene, ethanol and methanol gases in the breath exhaled via the mouth and nose, in order to identify the major trace gas compounds for breath analysis. All the measurements were made before and after brushing with toothpaste and baking soda.

Mouth-exhaled breath vs. nose-exhaled breath was investigated using a $\mathrm{CO}_{2}$ laser photoacoustic system (LPAS), a well-known method in the field of trace gas detection, used in our study for quantitative multi-component determination.

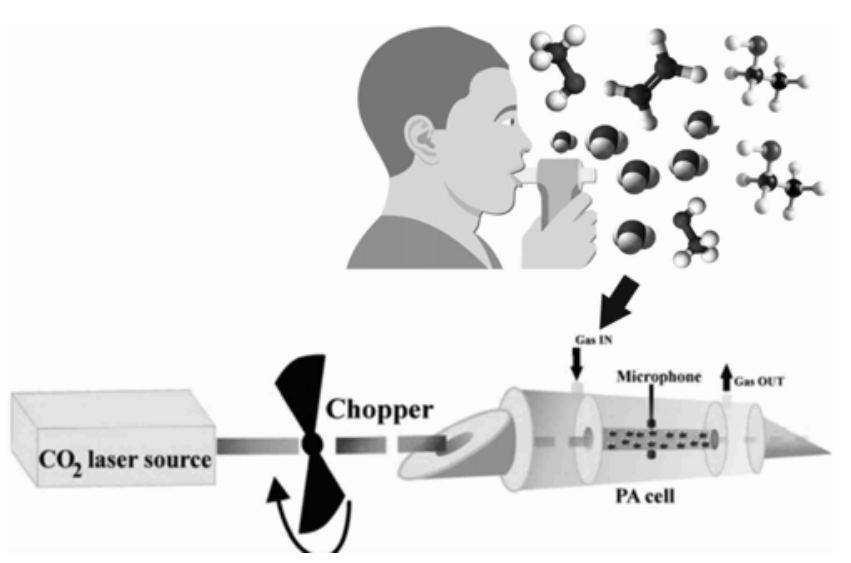

The levels of all four trace gases are much lower for nose breathing compared with mouth breathing. Compared to initial concentrations, the levels of all four trace gases are much lower after brushing with toothpaste and after brushing baking soda.

To analyze and identify the major trace gas compounds from breath, the volunteers should be instructed to use toothpaste before each breath test sampling, to keep the oral bacteria under control. Even though it is conceivable that some compounds may have their origins in the nasal passages and sinuses, to avoid mouth contamination of the breath samples also nose breath analysis should be carried out. In order to identify the major sources of ethylene, ammonia, ethanol, and methanol compound the measurements should be carried out of both nasal-breathing route and mouth-breathing route.

These findings may lead to a procedure whereby subjects should give breath samples so as endogenous biomarkers are less possible contaminated by other sources.

\section{INTRODUCTION}

The field of analysis of the volatile organic compounds has attracted a considerable amount of scientific interest during the last decade, but one of the challenges in the field of analysis of the volatile trace gas in exhaled breath is to be able to relate their concentrations to the corresponding plasma levels. ${ }^{1-3}$ In contrast to NO, which is predominantly generated in the bronchial system, volatile organic compounds (VOCs) are mainly blood borne and therefore enable monitoring of different processes in the body. The effort is made to detect and quantify ammonia, ethylene, ethanol and methanol that are present in the breath via mouth and nose but it is also known that trace gases can be also emitted from mucus, saliva and aerosols created in the respiratory tract. ${ }^{2,3}$ It is clearly desirable to differentiate these spurious sources from those compounds released at the alveolar interface if breath analysis is to become a valuable clinical diagnostic tool for systemic, metabolic disease and physiological studies. ${ }^{1-3}$

\footnotetext{
${ }^{*}$ Corresponding author: cristina.achim@inflpr.ro
} 
Breath analysis continues to be an interesting field for noninvasively diagnosis of serious illnesses. Biomarker analysis in breath may be the most simple, rapid and safest way to accurately determine the stage or the severity of a dysfunction. ${ }^{36-38}$ Although numerous biomarkers have been identified so far, very little is known about their origin, if they are metabolic or not. ${ }^{4-6,36-38}$

Trace constituents in the exhaled breath generally have both endogenous and exogenous sources. These volatiles may be produced by cellular metabolic processes, or inhaled/absorbed from exogenous sources. The exogenous volatiles are inhaled into and absorbed through the lungs or absorbed through the skin. They originate from many solvents and petroleum based products. The endogenous volatiles are generated by the cellular biochemical processes of the body. Thus, measurement of VOCs in the breath can provide a window into the biochemical processes of the body. The origin of many endogenous VOCs is not known. Additional work needs to be performed to learn about the important biochemical pathways for all of the volatiles that can be detected. ${ }^{7}$

A large variety of biomarkers are produced endogenously, while others are associated with bacterial growth in the oral cavity or in the upper respiratory tract.

A wide variety of different bacteria (between 700-1000 bacterial species and not-yet-cultivated phylotypes) has been found as colonizers of the human oral cavity. ${ }^{8}$ It has been estimated that more than half of them still remain uncultivated.

In 2016, Sowmya Y., ${ }^{8}$ published in Journal of Dental Sciences, the classification oral bacteria based on Gram's Staining (Gram Positive, Gram negative) and based on the effect of oxygen bacteria (obligate aerobe, micro aerophilic, facultative anaerobes, obligate anaerobe).
In mouth, some of the common genuses of bacteria are Streptococci, Neisseria, Fusobacterium, Prevotella, Bifidobacterium, Lactobacillus, Actinomyces, Propionibacterium, Treponema, Veillonella, Arachnia, Bacteroides, Eubacterium, Leptotrichia, Peptococcus, Peptostreptococcus, Selenomonasand and other anaerobic bacteria (see Table 1).

Resident oral micro flora takes part in the normal development of the oral cavity and in the maintenance of healthy life. Oral cavity is one of the parts of the body which consists of large variety of microbes. The ecological balance should be maintained to keep the human oral cavity healthy. These microbes are generally kept under control with a healthy diet and proper oral hygiene, brushing teeth at least twice a day. The most used products for oral hygiene are cosmetic toothpastes, baking soda, and alcohol mouthwashes. ${ }^{8}$ To better recognize an unhealthy breath, it is necessary to establish a healthy one. Although the health status of patients can be identified with a single breath, collecting a pure breath sample is not as simple as it may seem. Therefore nasal breath analysis has been recommended to avoid contamination of alveolar breath with mouth gas. The aspects of sampling procedure must be studied in detail in the case of measuring breath biomarkers.

Ethylene, methanol, ethanol and ammonia are nowadays known indirect biomarkers for various diseases and malfunctions of the human body (in Table 2 some of these biomarkers are displayed).

Elevation of breath levels of some of these gases (ammonia, ethane, isoprene, butane, nitric oxide, ethanol, carbon monoxide, methane, hydrogen sulphide, and acetone) is associated with a variety of metabolic and pathologic conditions. ${ }^{9-13,17,18}$

Table 1

Classification of bacteria $^{8}$

\begin{tabular}{|c|c|c|c|}
\hline \multicolumn{2}{|c|}{ Gram Positive } & \multicolumn{2}{|c|}{ Gram Negative } \\
\hline Cocci & Rods & Cocci & Rods \\
\hline Abiotrophia & Actinomyces & Moraxella & Campylobacter \\
\hline Peptostreptococcus & Bifidobacterium & Neisseria & Capnocytophaga \\
\hline Streptococcus & Corynebacterium & Veillonella & Desulfobacter \\
\hline Stomatococcus & Eubacterium & & Desulfovibrio \\
\hline & Lactobacillus & & Eikenella \\
\hline & Propionibacterium & & Fusobacterium \\
\hline & Pseudoramibacter & & Haemophilus \\
\hline & Rothia & & Leptotrichia \\
\hline
\end{tabular}


Table 2

The correlation of biomarkers with various malfunctions at humans ${ }^{9-13}$

\begin{tabular}{|c|c|c|c|c|}
\hline Biomarker & $\begin{array}{l}\text { Vibrational } \\
\text { absorption } \\
\quad(\mu \mathrm{m})\end{array}$ & $\begin{array}{c}\text { Typical } \\
\text { concentrations of } \\
\text { healthy individuals }\end{array}$ & $\begin{array}{l}\text { Concentrations } \\
\text { range in unhealthy } \\
\text { individuals }\end{array}$ & Disease/metabolic disorder \\
\hline acetone & 7.3 & $477 \mathrm{ppb}$ & $500-600 \mathrm{ppb}$ & $\begin{array}{l}\text { lung cancer, diabetes, brain seizure, } \\
\text { non-alcohol fatty liver-disease in children }\end{array}$ \\
\hline acetaldehyde & $9.2-9.8$ & $20-27 \mathrm{ppb}$ & $33-37 \mathrm{ppb}$ & $\begin{array}{l}\text { alcoholism, liver related diseases, lung } \\
\text { cancer }\end{array}$ \\
\hline ammonia & $9.2 ; 10.3$ & 30- $688 \mathrm{ppb}$ & $1.5-6 \mathrm{ppm}$ & renal disease, H. Pylori infection \\
\hline carbon monoxide & 4.7 & $0.5 \mathrm{ppm}$ & $5 \mathrm{ppm}$ & $\begin{array}{l}\text { respiratory infection, oxidative stress, } \\
\text { anaemias }\end{array}$ \\
\hline carbon sulfide & 3.4 & 3ppt-30ppb & $0.5 \mathrm{ppm}$ & $\begin{array}{l}\text { liver failure, cystic fibrosis, acute lung } \\
\text { transplant rejection }\end{array}$ \\
\hline ethane & 3.3 & $0.12 \mathrm{ppb}$ & $3.5 \mathrm{ppb}$ & $\begin{array}{c}\text { chronic respiratory diseases, lipid } \\
\text { peroxidation }\end{array}$ \\
\hline ethanol & 9.3 & $30-1663 \mathrm{ppb}$ & $6130 \mathrm{ppb}$ & diabetes mellitus \\
\hline ethylene & $3.3 ; 10.5$ & $3-100 \mathrm{ppb}$ & $750 \mathrm{ppb}$ & $\begin{array}{l}\text { oxidative stress after haemodialysis, } \\
\text { radiation damage to the skin, lipid } \\
\text { peroxidation }\end{array}$ \\
\hline formaldehyde & 3.59 & $0.3-0.6 \mathrm{ppm}$ & $0.45-1.2 \mathrm{ppm}$ & gastro-esophageal and breast cancer \\
\hline hydrogen & $\begin{array}{l}\text { not feasible in } \\
\text { IR }\end{array}$ & - & - & $\begin{array}{l}\text { ingestion in infants, intestinal upset, } \\
\text { colonic fermentation }\end{array}$ \\
\hline methane & $3.3 ; 7.9$ & $0.5 \mathrm{ppm}$ & $4 \mathrm{ppm}$ & intestinal problems, colonic fermentation \\
\hline methanetiol & $3.45-3.28$ & $2-4 \mathrm{ppb}$ & $20.30 \mathrm{ppb}$ & halitosis \\
\hline methanol & $9.6-9.7$ & $\begin{array}{l}150-200 \mathrm{ppb} ; 32- \\
1683 \mathrm{ppb}\end{array}$ & $500 \mathrm{ppb}$ & $\begin{array}{l}\text { nervous system disorder, dialysis } \\
\text { complications }\end{array}$ \\
\hline $\begin{array}{l}\text { nitrogen monoxide/ } \\
\text { nitric oxide }\end{array}$ & 5.2 & $14-17 \mathrm{ppb}$ & $100 \mathrm{ppb}$ & $\begin{array}{l}\text { asthma bronchiectasis, hypertension, } \\
\text { rhinitis, lung diseases }\end{array}$ \\
\hline pentane & 6.8 & $7-10 \mathrm{ppb}$ & $16 \mathrm{ppb}$ & $\begin{array}{l}\text { liver diseses, peroxidation lipids, } \\
\text { schizophrenia breast cancer }\end{array}$ \\
\hline sulfur compounds & - & - & $0.03-1 \mathrm{ppb}$ & lung cancer, hepatic diseases and malodor \\
\hline hydrocarbons & - & - & $0.06-3 \mathrm{ppb}$ & $\begin{array}{c}\text { airway inflammation, lung cancer, lipid } \\
\text { peroxidation }\end{array}$ \\
\hline
\end{tabular}

Nevertheless, there are many concerns if some biomarkers are true endogenous or they may have some exogenous sources. Methanol and ethylene were found to be metabolic products rather than exogenous compounds. ${ }^{17}$ The detected ammonia and ethanol can largely be generated in the oral cavity. Since ammonia is processed in the liver, kidneys and skeletal muscles, previous studies ${ }^{14-16}$ demonstrated that people with kidney failure have a marked odor of ammonia on their breath, which can be an indicator of this disease. Ammonia and ammonium ions are converted into urea in the liver through the urea cycle and the urea is then transported through the bloodstream to be excreted into urine by the kidneys. The reversibility of the process requires an equilibrium concentration of ammonia related to the blood urea nitrogen loading of the blood. As small molecules, ammonia and ammonium ions can penetrate the blood-lung barrier, and appear in exhaled breath. In the case of kidney dysfunction, urea is unable to be excreted, causing an excessive build up of ammonia in the blood. The concentration of ammonia from respiration at the beginning of dialysis, being between $1500 \mathrm{ppb}$ and $2000 \mathrm{ppb}$ and at the end of dialysis treatment, between 150 to $200 \mathrm{ppb}^{14-21}$ Clearly, further studies are required involving a larger cohort of healthy volunteers and also of patients suffering from uraemia (liver and kidney disease) for which mouth-exhaled ammonia levels are known to be elevated above normal. ${ }^{14-16}$

Several other research papers already establish the normal levels for these compounds in the human breath. The levels were reported to be 32$1683 \mathrm{ppb}$ for methanol and 0-1663 ppb for ethanol. Exhaled ammonia for healthy persons ranges between 0.1 and $688 \mathrm{ppb}$. Ethylene resulting from the lipid peroxidation in the human body was one of the first breath compounds studied, being reported to range between 3 and $100 \mathrm{ppb}^{2,7,19-21}$

The level of compounds in human breath can change slightly depending on every person oral hygiene (if these persons used care products before breath collection or not), and also on the time and 
day that the breath sample was taken. Therefore, each person has a unique "breathprint" (or chemical composition), that remain distinct and relatively stable. ${ }^{3,9,22,23}$

In the process of determining a way to collect the most correct breath sample, the aim of this study was to investigate exhaled breath via both mouth and nose to identify the better route for breath analysis when detecting the important compounds like methanol, ethanol, ammonia and ethylene. This study also investigated the influence of oral basic care on exhaled concentrations of these endogenous biomarkers. Our findings may lead to a procedure whereby patients should give breath samples so as endogenous biomarkers are less possible contaminated by other sources.

\section{METHOD}

To distinguish endogenous biomarkers from contaminants originating from environment or bacteria, mouth-exhaled breath and nose-exhaled breath have been investigated using a $\mathrm{CO}_{2}$ LPAS. This method is very sensitive and selective and well known in the field of trace gas detection (ppb level). It was used in our study for quantitative determination in real time of ethylene, methanol, ethanol and ammonia, with operational simplicity, easy calibration, and no need for sample preparation.

Our LPAS system has been described previously in several research papers. . $^{14,21,24,25,36-38}$ The main components of the LPAS detector are a frequency-stabilized line-tunable $\mathrm{CO}_{2}$ laser and a resonant photoacoustic (PA) cell in which the gas concentration is measured. Multicomponent mixtures can be measured with high sensitivity and necessary selectivity by this system for the molecules that possess high absorption strengths and a characteristic absorption pattern in the wavelength range of the $\mathrm{CO}_{2}$ laser. ${ }^{26,36-38}$

To summarize, a breath sample is introduced into the PA cell by using a vacuum/gas handling system. As breath gases entered the PA cell of the system, the tunable $\mathrm{CO}_{2}$ laser excites the gas molecules. The light energy used for vibrational excitation of molecules is then converted to heat that give rise to a pressure variation in a closed volume (an acoustic wave) that can be detected with sensitive miniature microphones placed inside the PA cell. The PA signal, $V$, is related to the gas concentration by:

$$
V=\alpha C S_{M} P_{L} c
$$

where $\alpha$ is the gas absorption coefficient at a given wavelength (in units of inverse centimeters and inverse atmospheres), $C$ is a constant of the cell, depending on geometry, measurement conditions, and modulation frequency (in units of Pascal centimeters per Watt), $S_{M}$ is the sensitivity of the microphone (in units Volts per Pascal), $P_{L}$ is the power of the incident laser radiation (in units of Watts); and $c$ is the trace gas concentration (usually given in units of percent, $\mathrm{ppmV}$, ppbV or $\mathrm{pptV}){ }^{24-26,36-38}$

Once the gas was analyzed by the lock-in amplifier, the digital data were introduced in the acquisition board and all the experimental data are processed in real time and stored by a computer.

Our measurement procedure to determine the concentrations of gases, involves these basic steps: cleaning of the cell, calibration of the cell or measurement of the cell responsivity, acquiring spectra of the ethylene, ammonia, methanol and ethanol vapors. For the measurements and detection of all four gases from breath, the laser was kept tuned where ethylene, methanol, ethanol and ammonia exhibit the strongest and characteristic peaks. ${ }^{26-28,36-38}$

The cleaning of the cell was carefully performed by successively flushing out with nitrogen purity of $6.0(99.9999 \%)$, at atmospheric pressure, executed each time when the cell filling was changed. An appropriate degree of the cell cleaning was considered to be achieved if the photoacoustic signal measured in nitrogen atmosphere had a fair low level, typically of 30 $\mu \mathrm{V}$. The PA cell responsivity was measured using a calibrated mixture of $0.996 \mathrm{ppmV}$ ethylene in nitrogen 6.0 (99.9999\%), supplied by Linde Gas, at atmospheric pressure. The 10P (14) line from the $\mathrm{CO} 2$ laser spectrum was selected for this task due to the fact that ethylene presents here the highest absorption of $30.4 \mathrm{~atm}^{-1} \mathrm{~cm}^{-1}$. The measured responsivity of the cell was $320 \mathrm{~cm} \mathrm{V/W}$.

The absorption spectra for all four gases (ethanol, methanol, ethylene and ammonia) was built by recording the values measured for one cell filling, by successively tuning the laser on the available lines. ${ }^{14,25-28}$

As sampling gases we used certified gases supplied by Linde Gas with following concentrations: for ethanol a calibrated mixture of $10.5 \mathrm{ppmV}$ ethanol in nitrogen 6.0, for methanol a calibrated mixture of $9.17 \mathrm{ppmV}$ methanol in nitrogen 6.0, for ethylene a calibrated mixture of $9.88 \mathrm{ppmV}$ ethylene diluted in nitrogen 6.0 and for ammonia a calibrated mixture of $10 \mathrm{ppmV}$ diluted in nitrogen 6.0. 
The gases concentration in the mixtures were chosen low enough to avoid the saturation effect and high enough to produce a significant value of the signal and the choice of nitrogen complies with two requirements: a buffer gas non-absorbing in the IR region and a gas closed to the real air composition. The absorption measurements were always performed at room temperature $\left(20-22^{\circ} \mathrm{C}\right)$.

The accumulation of breathing air can be made using aluminized multi-patient collection bags (designed to collect multiple samples from patients and hold a sample for maximum 6 hours) with a volume of $750 \mathrm{~mL} .^{25,36-38}$ The sample bag system is assured by a tee-mouthpiece assembly together with a discard bag (for mouth breathing) and one tube for nasal breathing (Fig. 1).

Practically, the subject places the mouthpiece or the tube in his mouth/nose, forming a tight seal around it with the lips/nose. A normal expiration is then made through the mouth or nose, in order to empty the lungs of as much air as required to provide the sample. ${ }^{24-26,36-38}$

The exhaled air is a heterogeneous gas. For a healthy individual, the first part of an exhaled breath, roughly $150 \mathrm{~mL}$, consists of "dead space" air from the upper airways (such as the mouth and trachea), where air does not come into contact with the alveoli of the lungs. The following part of a breath, about $350 \mathrm{~mL}$, is "alveolar" breath, which comes from the lungs, where gaseous exchange between the blood and breath air takes place. ${ }^{29}$ Dead space air can be interpreted as essential for the detection or only contaminated, and depends on the type of molecule detected from the breath test. For example, the dead space for NO is used to quantify the amount of the molecules. In the case of an asthmatic patient, if the airways are inflamed, a high-level of NO is released into the airways and into the dead space air. But for VOCs exchanged between blood and alveolar air, the dead space air is a "contaminant" diluting the concentrations of VOCs when breath air is collected. In terms of the origin of the collected breath gases, there are three basic collection approaches: $:^{29}$ (1) upper airway collection for NO test; this means that only deadspace gas is collected (it is only for the NO test); (2) alveolar collection; this means that pure alveolar gas is collected (for tests of other inorganic gases and VOCs); (3) a mixed expiratory collection; this means that total breath air, including dead space air and alveolar gas is collected (appropriate for tests of special gases and VOCs). Because the mixed expiratory collection method is easy to perform in spontaneously breathing subjects requiring no additional equipment, it has been most frequently used in practical applications. However, concentrations of endogenous substances in alveolar air are two to three times higher than those found in mixed expiratory samples, because there is no dilution by dead space gas. Collection of breath air can be performed for a single breath or for collection of individual breathes over a certain period of time. If the sample is collected through a single breath, one has to be sure that this single breath is representative. $^{21,29}$

For the mouth exhaled breath sample, the first portion of the expired air is directed into the discard bag (with the role in collection of the "dead-space" air: the first portion of an expired breath), while the alveolar air is diverted to the collection bag. When an adequate sample is collected, the subject stops exhaling and removes the mouthpiece/tube.

After the volunteer exhaled via the mouth or the nose and the sample is collected, the gas from the sample is transferred into the PA cell and can be analyzed immediately or later. In either case, it is recommendable to seal the large port with the collection bag port cap furnished with the collection bag. The use of the port cap assures that the sample volume will not be lost due to a leak. Its use also avoids the contamination of the sample by gas diffusion through the one-way valve in the large port, if the sample is stored for a long period of time prior to its analysis.

We involved 15 healthy (5 women and 10 men) volunteers with ages between 27 and 36 (coworkers of our institute) in this study (see Table 3 ).

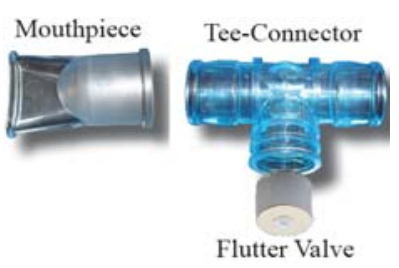

a) Mouthpiece and tee-connector

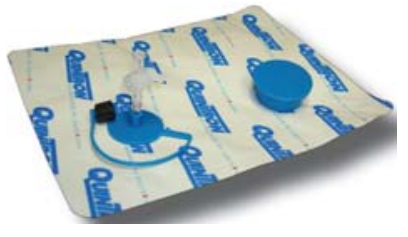

b) $0.75 \mathrm{~L}$ aluminum-coated bag

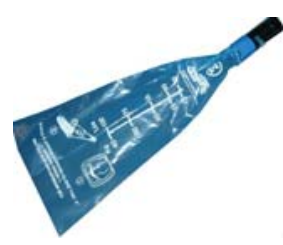

c) $0.40 \mathrm{~L}$ discard bag

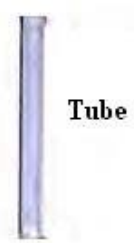

d) Tube for nasal breathing

Fig. 1 - The mouth and nose exhaled breath sample collection system. 
Table 3

Subject's information's for the study

\begin{tabular}{c|c|c|c|c|c|c}
\hline Subject & Gender & Age & Subject height $(\mathrm{m})$ & $\begin{array}{c}\text { Subject weight } \\
(\mathrm{kg})\end{array}$ & BMI & $\begin{array}{c}\text { Total number of } \\
\text { measurements }\end{array}$ \\
\hline S1 & Female & 27 & 1.55 & 48.0 & 20 & 120 \\
S2 & Female & 28 & 1.55 & 52.0 & 21.6 & 120 \\
S3 & Female & 31 & 1.62 & 54.0 & 20.6 & 120 \\
S4 & Female & 33 & 1.70 & 58 & 20.1 & 120 \\
S5 & Female & 32 & 1.68 & 57 & 20.2 & 120 \\
S6 & Male & 29 & 1.78 & 95.0 & 30 & 120 \\
S7 & Male & 30 & 1.81 & 73.0 & 22.3 & 120 \\
S8 & Male & 36 & 1.80 & 85.0 & 26.2 & 120 \\
S9 & Male & 36 & 1.80 & 83.0 & 25.6 & 120 \\
S10 & Male & 35 & 1.76 & 87.0 & 28.1 & 120 \\
S11 & Male & 36 & 1.71 & 98.0 & 28.4 & 120 \\
S12 & Male & 36 & 1.80 & 78.0 & 23.2 & 120 \\
S13 & Male & 34 & 1.81 & 70.0 & 20.9 & 120 \\
S14 & Male & 33 & 1.83 & 72.0 & 23.5 & 120 \\
S15 & Male & 31 & 1.75 & &
\end{tabular}

Healthy subjects were non- or ex-smokers, nonalcoholic, non-renal, non-diabetic without chronic mental or physical health problems and without any recent antibiotic therapy. Prior to the analysis of breath, the volunteers were asked to avoid for at least 6 hours before or at any time during the breath sample collection: alcohol and coffee, food or beverages and to refrain from exercise in the morning. On the day prior the test, products such as onions, leeks, eggs, and garlic should be avoided. Information was asked regarding age, body weight and body height, time and nature of the least meal and drink, recent exercise activity, medication and smoking status (see Table 3).

It should be pointed out that all the data published about the volunteers were undertaken with the understanding and written consent of each volunteer.

\section{RESULTS AND DISCUSSION}

All breath samples were given in the laboratory every day between 08:00 am and 13:00 pm (during this time, they were asked to avoid drinking anything else but water in moderation) over a period of one month (120 breath samples/subject).

Then, a toothpaste study was conducted, where breath samples were taken before brushing and 10 minutes after brushing with toothpaste and rinsing with tap water. The same procedure was used for baking soda.

We have carried out a photoacoustic spectroscopy study of the mouth exhaled breath $v s$. nose exhaled breath concentrations of four trace gases: ethylene, methanol, ethanol and ammonia.
These gases present strong absorption features in the wavelength range of the $\mathrm{CO}_{2}$ laser. We chose the laser line which corresponds to the highest absorption coefficient for each gas (see Table 4).

An essential parameter in the biomarkers analysis is the responsivity $R(\mathrm{cmV} / \mathrm{W})$ of the PA cell which depends on the pressure of the gas inside the cell. An optimized acoustically resonant PA cell was used with a responsivity of $320 \mathrm{cmV} / \mathrm{W}$ at atmospheric pressure. The initial pressure in the sample bags filled by the healthy volunteers differs from one case to other and it is necessary to know the pressure dependence of the PA cell responsivity. The exhaled air sample was transferred to the PA cell at a controlled flow rate of $36 \mathrm{~L} / \mathrm{h}$ (600 sccm: standard cubic centimeters per minute), and the total pressure of the gas in the cell was measured, applying then the correction factor for the responsivity according to the results from Table 5 .

To analyze the mouth and nose exhaled bags contents, we evacuated firstly the extra gas by the vacuum handling system, and then we flushed the system with pure nitrogen at atmospheric pressure for 30 minutes.

For determining the detection of all four gases, the $\mathrm{CO}_{2}$ laser was kept tuned (see Table 4) first to the 10P(14) laser line where ethylene exhibited the strong and characteristic peak, then at $9 \mathrm{P}(34)$ where methanol exhibited the highest absorption coefficient, 9R(22) and 9R(30) where ethanol and ammonia exhibited strong and characteristic peaks. ${ }^{19,25-29}$

Figures 2-5 show the average concentrations of ethylene, methanol, ethanol and ammonia, for a single healthy volunteer both the mouth exhaled breath and the nose exhaled breath, before and after brushing with toothpaste and baking soda, followed by rinsing with tap water. 
Table 4

Gases measured by mouth $v s$. nasal breathing ${ }^{14,25-28}$

\begin{tabular}{c|c|c|c}
\hline Gas & $\mathrm{CO}_{2}$ laser line & $\begin{array}{c}\text { Line wavelength } \\
{[\mu \mathrm{m}]}\end{array}$ & $\begin{array}{c}\text { Absorption coefficient } \\
{\left[\mathrm{cm}^{-1} \mathrm{~atm}^{-1}\right]}\end{array}$ \\
\hline ethylene & $10 \mathrm{P}(14)$ & 10.529 & 30.4 \\
methanol & $9 \mathrm{P}(34)$ & 9.673 & 16.39 \\
ethanol & $9 \mathrm{R}(22)$ & 9.258 & 4.08 \\
ammonia & $9 \mathrm{R}(30)$ & 9.217 & 57.1 \\
\hline
\end{tabular}

Table 5

The responsivity of the PA cell against the pressure

\begin{tabular}{c|c}
\hline $\begin{array}{c}\text { Pressure } \\
(\text { mbarr })\end{array}$ & $\begin{array}{c}\text { Responsivity } \\
(\mathrm{cm} / \mathrm{W})\end{array}$ \\
\hline 400 & 103 \\
510 & 170 \\
610 & 220 \\
730 & 275 \\
820 & 320 \\
870 & 340 \\
915 & 370 \\
970 & 385 \\
\hline
\end{tabular}

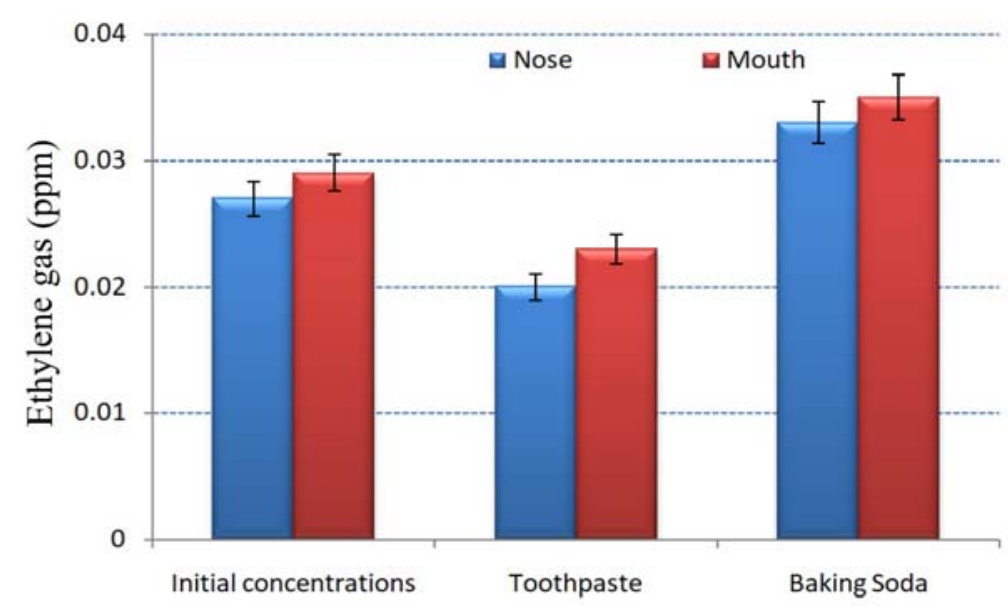

Fig. 2 - Ethylene gas average level from human respiration by nose $v s$. mouth (with error bars).

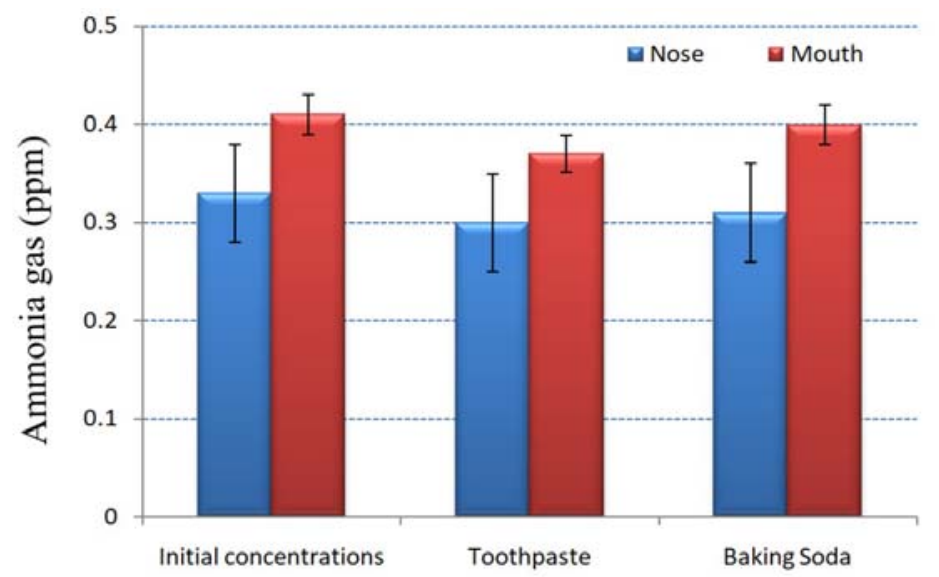

Fig. 3 - Ammonia gas average level from human respiration by nose vs. mouth (with error bars). 


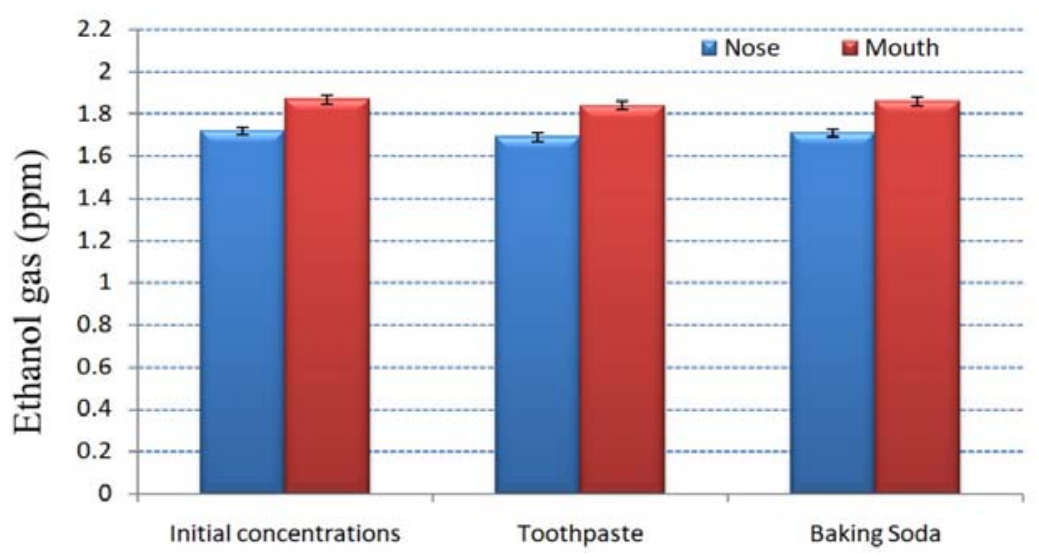

Fig. 4 - Ethanol gas average level from human respiration by nose $v s$. mouth (with error bars).

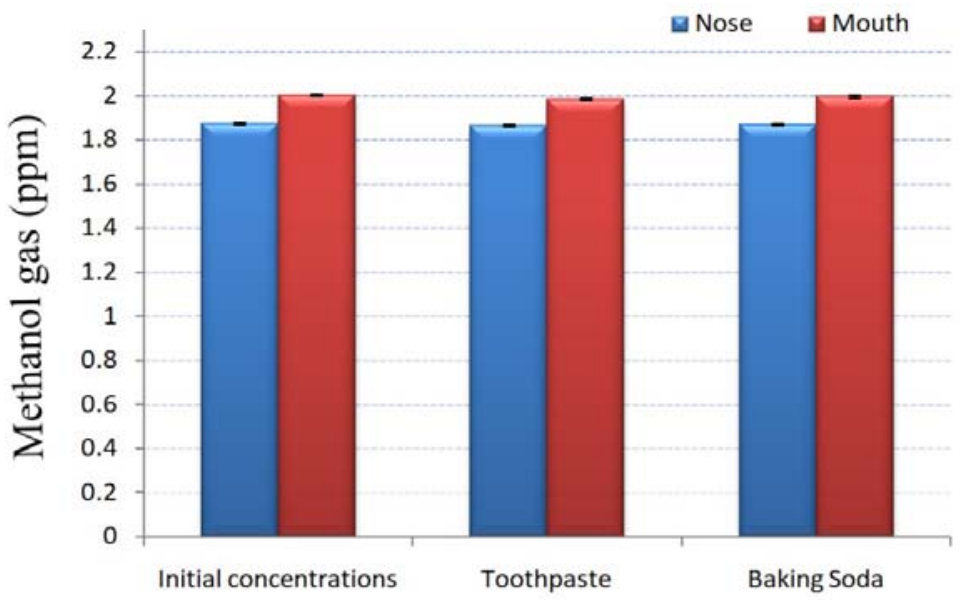

Fig. 5 - Methanol gas average level from human respiration by nose $v s$. mouth (with error bars).

The initial median values of ethylene concentration for the samples of mouth exhaled breath are about $0.029 \pm 0.010 \mathrm{ppm}$, while these values for the samples of nose exhaled breath are about 0.027 $\pm 0.030 \mathrm{ppm}$. For other gases like: ammonia - the concentrations are $0.41 \pm 0.05 \mathrm{ppm}$ and $0.33 \pm$ $0.05 \mathrm{ppm}$, for ethanol the concentrations are $1.87 \pm$ $0.4 \mathrm{ppm}$ and $1.72 \pm 0.5 \mathrm{ppm}$ and for methanol the values are: $2.000 \pm 0.09 \mathrm{ppm}$ and $1.875 \pm 0.04 \mathrm{ppm}$.

For initial concentrations, the levels of all four trace gases are lower for nose breathing with $6.9 \%$ for ethylene, $6.3 \%$ for methanol, $8 \%$ for ethanol and $19.5 \%$ for ammonia compared to mouth breathing.

After toothpaste washing, the median values of ethylene concentration for the samples of mouth exhaled breath are about $0.023 \pm 0.018 \mathrm{ppm}$, while these values for the samples of nose exhaled breath are about $0.02 \pm 0.011 \mathrm{ppm}$. For ammonia the concentrations are $0.37 \pm 0.05 \mathrm{ppm}$ and $0.33 \pm$ $0.08 \mathrm{ppm}$, for ethanol the concentrations are $1.84 \pm$ $0.5 \mathrm{ppm}$ and $1.69 \pm 0.3 \mathrm{ppm}$ and for methanol the values are: $1.985 \pm 0.5 \mathrm{ppm}$ and $1.865 \pm 0.5 \mathrm{ppm}$.
In the case of volunteers washing their teeth with toothpaste, the levels of all four trace gases are lower for nose breathing with $13 \%$ for ethylene, $6.1 \%$ for methanol, $8.2 \%$ for ethanol and $11 \%$ for ammonia, compared to mouth breathing.

After baking soda washing, the median values of ethylene concentration for the samples of mouth exhaled breath are about $0.035 \pm 0.015 \mathrm{ppm}$, while these values for the samples of nose exhaled breath are about $0.033 \pm 0.05 \mathrm{ppm}$. For ammonia the concentrations are $0.4 \pm 0.01 \mathrm{ppm}$ and $0.31 \pm$ $0.016 \mathrm{ppm}$, for ethanol the concentrations are $1.86 \pm 0.9 \mathrm{ppm}$ and $1.71 \pm 0.5 \mathrm{ppm}$ and for methanol the values are: $1.995 \pm 0.9 \mathrm{ppm}$ and $1.87 \pm 0.3 \mathrm{ppm}$.

In the case of volunteers washing their teeth with baking soda, the levels of all four trace gases are lower for nose breathing with $5.7 \%$ for ethylene, $6.2 \%$ for methanol, $8.1 \%$ for ethanol and $22.5 \%$ for ammonia compared to mouth breathing.

Compared to initial concentrations, the levels of all four trace gases are lower after brushing with toothpaste or with baking soda. In the same time, 
the levels of all four trace gases are lower after brushing with toothpaste compared to concentrations measured after brushing with baking soda.

The most common types of dental disease are tooth decay (cavities, dental caries) and gum diseases, including gingivitis, and periodontitis. Regular brushing consists of brushing twice a day: after breakfast and before going to bed.

To analyze and identify the major trace gas compounds from breath, the volunteers were trained to wash the mouth with toothpaste before each breath test sampling, to avoid oral bacteria, ${ }^{30,31,33-35}$ because a proper oral hygiene kept the oral bacteria under control.

Even though it is conceivable that some compounds may have their origins in the nasal passages and sinuses, to avoid mouth contamination of the breath samples also nose breath analysis should be carried out. In order to identify the major sources of ethylene, ammonia, ethanol and methanol compounds the measurements should be carried out of both nasal-breathing route and mouth-breathing route. ${ }^{3,33-35,39-41}$

\section{CONCLUSIONS}

LPAS has the potential to be a viable tool for monitoring real-time concentrations of ethylene, methanol, ethanol and ammonia in human breath. Being able to extract a signal from flowing breath samples, it provided the advantage of collecting large amounts of data in a short period of time. Furthermore, the sensitivity and accuracy were highly supportive of the results found in previous literature. ${ }^{14,21,24-29,36-38}$

Determinations have been performed using real time LPAS for the breath of five healthy volunteers, as they exhaled via the mouth and the nose after brushing with toothpaste and baking soda, each morning over a period of one month. Four trace compounds have been quantified and concentration distributions have been obtained. Of these compounds, the levels of ethylene, methanol, ethanol and ammonia are lower in the noseexhaled breath than in the mouth-exhaled breath, indicating that these compounds are somewhat generated in the mouth with little being released at the alveolar interface.

These results indicate that contamination of alveolar breath exhaled via the mouth can occur and if breath analysis is to be used to diagnose metabolic diseases, then analyses should be carried out of both mouth- and nose-exhaled breath to identify the major sources of particular trace compounds.

Generally, the level of compounds in human breath can change slightly depending on every person oral hygiene, on the time and day that the breath sample was taken, each person having a unique "breathprint" (or chemical composition), that remain distinct and relatively stable. More extensive studies with a larger number of volunteers using mouth $v s$. nasal monitoring may add clarity to this preliminary research.

As future work, more research is needed to investigate the exhaled breath via both mouth and nose before and after brushing with toothpaste/baking soda, by keeping the present determinations as reference (with a larger number of volunteers).

Acknowledgements. This work was supported by a grant of the Ministry of National Education and Scientific Research, RDI Program for Space Technology and Advanced Research STAR, IMAH, project no. 153 and to the National Authority for Research, and Innovation, to Nucleus programme-contract LAPLAS VI, no. $6 \mathrm{~N} / 2019$. The time and effort provided by the volunteers is greatly appreciated.

\section{REFERENCES}

1. C. Lourenço and C. Turner, Metabolites, 2014, 4, 465.

2. W. Miekisch, J. K. Schubert, G. F. Noeldge-Schomburg, Clin. Chim. Acta., 2004, 347, 25.

3. T. Wang, A. Pysanenko, K. Dryahina, P. Spaněl, D. Smith, J. Breath Res., 2008, 2, 037013.

4. M. F Alyssa, L. M. Benjamin, R. M. Ivan, Appl. Phys. Lett., 2013, 103, 133703.

5. S. Patrick, D. Kseniya, S. David, J. Breath Res., 2013, 7, 017106.

6. T. Y. Khalid, S. Saliha, J. Greenman, B de Lacy Costello, C. S. J. Probert and N. M. Ratcliffe, J. Breath Res., 2013, 7, 017114

7. P. J. Mazzone, J.Thoracic Oncol., 2008, 3, 774.

8. Y. Sowmya, Research and Reviews: J. Dental Sci., 2016, 4,1 .

9. C. Turner, P. Spanel, D. Smith, Physiol. Meas. 2006, 27, 637.

10. M. Simic, N. Ajdukovic, I. Veselinovic, M. Mitrovic, M. Djurendic-Brenesel, Forensic Sci. Int., 2012, 216, 97.

11. T. Hibbard, A. J. Killard, J. Breath Res., 2011, 3, 037101.

12. M. Karlsson, Student thesis. Umea University, Faculty of Science and Technology, Department of Physics, 2014.

13. D. J. Kearney, T. Hubbard, D. Putnam, Digestive Diseases and Sciences, 2002, 47, 2523.

14. C. Popa, D. C. A. Dutu, R. Cernat, C. Matei, A. M. Bratu, Ş. Banita and D. C. Dumitras. Appl. Phys. B, 2011, 105, 669.

15. O. S.W Damink, N. E. Deutz, C. H. Dejong, P. B. Soeters and R. Jalan, Neurochem. Int., 2002, 41,177.

16. I. D. Weiner, E. M. William and J. M. Sands, Clin. J. Am. So.c Nephrol., 2014, 10, 1444.

17. J. D. Pleil, M. A. Stiegel, T. R. Risby, J. Breath Res., 2013, 7, 017107. 
18. A.W. Boots, J. J. van Berkel, J. W. Dallinga, A. Smolinska, E. F. Wouters, F. J. van Schooten, J. Breath Res., 2012 , 6, 027108

19. B. W. M. Moeskops, M. M. L. Steeghs, K. van Swam, S. M. Cristescu, P. T. J. Scheepers and F. J. M. Harren, Physiological Measurements, 2006, 27, 1187.

20. D. J. Paetznick, G. A. Reineccius, T. L. Peppard, J. M. Herkert, P. Lenton, J. Breath Res., 2010, 4, 017106.

21. C. Popa, N. Verga, M. Pațachia, Ş. Băniță, C. Matei, and D. C. Dumitrass, Rom. Rep. Phys., 2014, 66, 120.

22. F. M. Schmidt, O. Vaittinen, M. Metsälä, M. Lehto, C. Forsblom, P. H. Groop, L., Halonen J. Breath Res., 2013, 7, 017109.

23. J. K. Schubert, W. Miekisch, K. Geiger, G. F. NöldgeSchomburg, Expert Rev. Mol. Diagn., 2004, 4, 619.

24. D. C. Dumitras, S. Banita, A. M. Bratu, R. Cernat, D. C .A Dutu, C. Matei, M. Patachia, M. Petrus and C. Popa, Infrared Phys.Techn. J., 2010, 53, 308.

25. D. C. Dumitras, D. C. A. Dutu, C. Matei, R. Cernat S. Banita, M. Patachia, A. M. Bratu, M. Petrus and C. Popa, Laser Physics, 2011, 21, 796.

26. D. C. Dumitras, D. C. A. Dutu, C. Matei, A. M. Magureanu, M. Petrus and C. Popa, JOAM, 2007, 9, 3655.

27. I. R. Ivascu, C. E. Matei, M. Patachia, A. M. Bratu, D. C. Dumitras, Rom. Reports Phys., 2015, 67, 1558

28. I. R. Ivascu, C. E. Matei, M. Patachia, A. M. Bratu, D. C. Dumitras Spectrochim. Acta Part A: Molec. Biomolec. Spectros., 2016, 163, 115.
29. A. M. Popa, A. M. Bratu, C. Matei, R. Cernat, A. Popescu, and D. C. Dumitras, Laser Physics, 2011, 21, 1336-1342.

30. L. O. Dahl and J. C. Muhler, J. Periodontol. 1995, 26, 43.

31. World Health Organization, 2012 from http://www.who.int/mediacentre/factsheets/fs318/en/.

32. G. McCracken, J. Janssen, M. Swan, N. Steen, M. de Jager and P. Heasman, J.Clinic. Periodontol., 2003, 30, 409. https://dx.doi.org/10.1034/j.1600-051x.2003.20008.x.

33. U. A. Bahadır and Ç. Hakan, J. Nat. Sci. Biol. Med., 2013 4, 14.

34. K. Curran, P. Yuan and D. Coyle, Int. J. Bioinform. Res. Appl., 2012, 28, 382.

35. D. Kovacs, A. Bikov, G. Losonczy, G. Murakozy and I. Horvath, J. Breath Res., 2013, 7, 017117.

36. M. Petrus and A. Bratu , Rom. Reports Phys., 2016, 68, 1140 .

37. D. C. Dumitras, A. M. Bratu, C. Popa, " $\mathrm{CO}_{2}$ LaserOptimization and Application", D. C. Dumitras (Ed.), 2012, Chapter 2.

38. C. Popa, J. Biomed. Opt., 2015, 20,051003. (doi: 10.1117/1.JBO.20.5.051003.)

39. C. Popa, M. Pațachia, Ș Băniță, and D. C. Dumitraş, Rev. Roum. Chim., 2013, 58, 779.

40. M. Petrus, A. Bratu, C. Popa, Rev. Roum. Chim., 2016, 61, 83.

41. C. Popa, M. Petrus, A. M. Bratu, Microchem. J., 2018 , 139, DOI 10.1016/j.microc.2018.02.030. 